\title{
The Fate of Atlantic Bluefin Tuna
}

\author{
Jean-Marc Fromentin ${ }^{1, *}$ \\ ${ }^{1}$ IFREMER, Centre de Recherche Halieutique Méditerranéenne et Tropicale, avenue Jean Monnet, BP 171, \\ 34203 Sète cedex, France. \\ *: Corresponding author : J. M. Fromentin, email address : jean.marc.fromentin@ifremer.fr
}

Since the mid-2000s, nongovernmental organizations (NGOs) have made Atlantic bluefin tuna (BFT) the archetype of overfishing and general mismanagement of the world fisheries. There are good reasons for this as BFT crystallizes most of the problems of many fisheries: severe overcapacity, open access in international waters, high market value, and deficient governance at both the international and national levels.

Because of this situation, Monaco has proposed that BFT be listed under Appendix 1 (the "most endangered" category) of the Convention of International Trade in Endangered Species of Wild Fauna and Flora (CITES). However, it is unclear whether current BFT stock status really meets the biological listing criteria for CITES; the media has sometimes exaggerated the threat to BFT, and BFT management has changed for the better during the past two years.

From a strict scientific standpoint, current scientific knowledge does not unequivocally support BFT listing under Appendix 1 (which bans international trade), but it fully supports Appendix 2 (which does not ban fishing in international waters or trade, but mandates monitoring by CITES and the International Commission for the Conservation of Atlantic Tunas).

If Monaco's proposal is adopted at the March CITES meeting in Doha, BFT will become the first commercially exploited marine species to be listed under Appendix 1. This could generate a revolution in fisheries management, as more than 100 exploited marine species are currently equally or more overfished than BFT-these include many species of sharks, rays, billfishes, sturgeons, salmons, eels, groupers, snappers, flat fish, deep sea fish, gadoids, shrimps, and clams. This could finally lead to the implicit substitution of current management fisheries organizations by CITES. Is CITES ready to manage the world fisheries in near future, and is it the right multilateral organization to do it? 